\title{
Tumor de células granulares perianal. Reporte de un caso y revisión de literatura
}

\author{
Fernando Grinóvero, Pamela Jacinto, Julieta Cittadini, Omar Rubén Miravalle, \\ Pablo Antonio Farina, Carlos Miguel Lumi \\ Centro Privado de Cirugía y Coloproctología. CABA, Argentina.
}

\begin{abstract}
RESUMEN
El tumor de células granulares fue descripto por Abrikossoff en 1926. Solo el $8 \%$ se localiza en el tracto gastrointestinal y es infrecuente su localización perianal. Acorde con la revisión de la bibliografía actual, este sería el trigésimo segundo caso reportado. EI TCG perianal es una lesión infrecuente y de difícil diagnóstico. Para su tratamiento es fundamental una resección quirúrgica completa con márgenes de resección libres, así como el examen inmunohistoquímico. Posteriormente, es necesaria la vigilancia estricta de los pacientes para detectar recidiva local, diseminación ganglionar y enfermedad a distancia que caracterizan al TCG maligno que presenta un pronóstico poco alentador.
\end{abstract}

Palabras claves: Tumor de células granulares; Tumor de Abrikossoff; Lesión perianal

\begin{abstract}
The granular cell tumor (GCT) was described by Abrikossoff in 1926. Only $8 \%$ is located in the gastrointestinal tract and its perianal location is rare. According to the current literature review, this would be the thirty-second reported case. Perianal GCT is a rare and difficult to diagnose lesion. For its treatment, a complete surgical resection with free resection margins is essential, as well as an immunohistochemical examination. Subsequently, strict surveillance of patients is necessary to detect local recurrence, lymph node dissemination, and distant disease characteristic of malignant GCTs, which have a poor prognosis.
\end{abstract}

Keywords: Granular Cell Tumor; Abrikossoff Tumor; Perianal Lesion

\section{INTRODUCCIÓN}

El tumor de células granulares (TCG) es una lesión infrecuente de la submucosa que se encuentra generalmente en la cavidad oral, localizándose en la lengua en un tercio de los casos. Alrededor del $8 \%$ de los TCG se localizan en el tracto gastrointestinal, siendo el esófago el responsable de la mayoría de estos casos seguidos por el colon. Otros sitios donde se lo puede encontrar incluyen la piel, mama, vía biliar, tractos respiratorio y genital. ${ }^{1-8}$

En 1926, Abrikossoff ${ }^{1}$ informó los primeros cinco casos de TCG, tres de los cuales estaban localizados en la lengua. Este autor postula que el tumor se origina en una célula muscular embrionaria e identificó el tumor como un mioma mioblástico. Posteriormente fueron ocurriendo cambios en la fisiopatología y así, en 1939, Leroux y Delarue postularon que el TCG no era de origen miogénico sino una acumulación no neoplásica de histiocitos granulares. En 1935, Feyrter y colaboradores propusieron la patogenia más aceptada y actual del tumor con un origen neural definiendo al TCG como un mioblastoma. Gullino et al., en 1949, usando inmunohistoquímica y microscopía electrónica, describieron el mioblastoma como una

Los autores declaran ausencia de conflictos de interés.

Fernando Grinóvero

fernando_grinovero@hotmail.com

Recibido: octubre de 2020. Aceptado: mayo de 2021. célula de Schwann debido a su positividad para S100 y al patrón de tinción de glucoproteína asociada a mielina. ${ }^{2,4,9}$

Al momento de esta revisión bibliográfica, hay informados en la literatura 31 casos de TCG perianales, lo que la convierte en una neoplasia anal con una baja frecuencia de presentación. 3,7,6,9,10

El TCG suele manifestarse entre la cuarta y sexta década de la vida y su prevalencia es mayor en las mujeres que en los hombres, con una relación de 1,5:1, no encontrándose diferencias entre razas. ${ }^{4,6,10,11}$

Generalmente el TCG se presenta como una lesión única, aunque también pueden aparecer múltiples lesiones de forma sincrónica o metacrónica en un 10-15 \% de los casos. $^{3}$

La extirpación local con márgenes libres es el tratamiento de elección en la localización perianal y, en aquellos pacientes con afectación de ganglios linfáticos, se recomienda la resección de los mismos durante la cirugía. 3,4,6,10,12

\section{PRESENTACIÓN DEL CASO}

Una paciente femenina de 63 años consulta por presentar una masa perianal asintomática, de 3 meses de evolución, con crecimiento progresivo desde su inicio.

Al examen proctológico se observa una lesión perianal, en cuadrante anterolateral izquierdo (horas 1 a 3 ) redondeada de aproximadamente unos $4 \mathrm{~cm}$, indurada, que al 


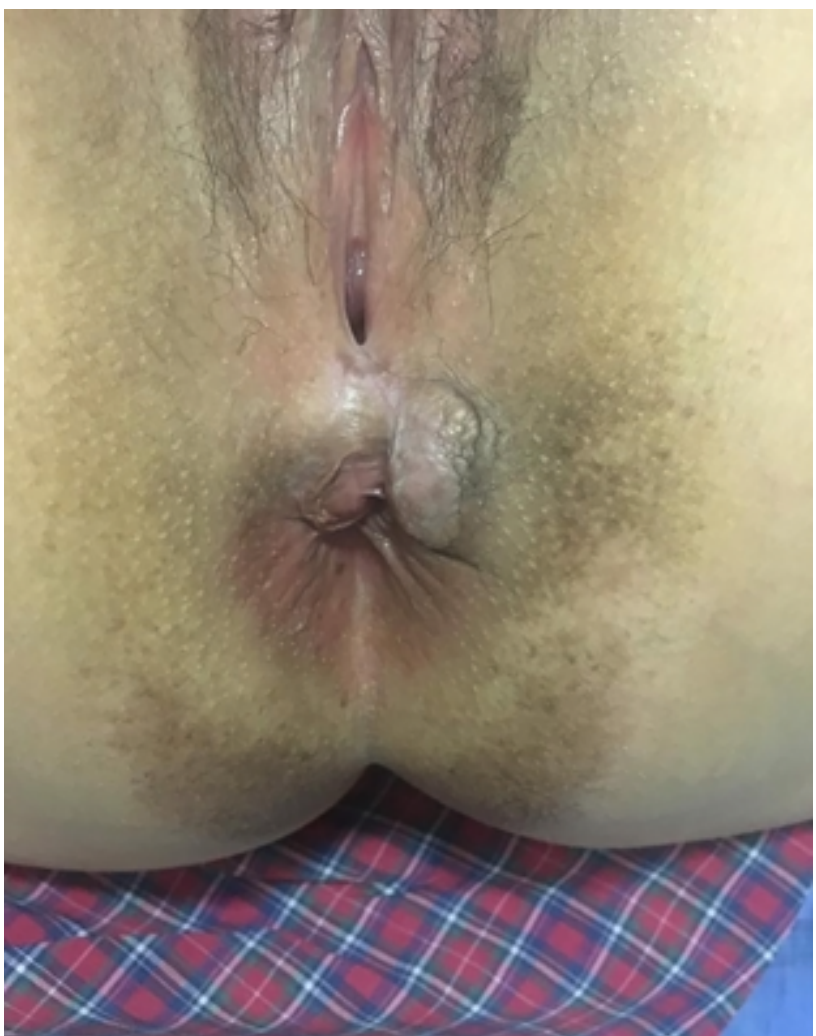

Figura 1: Lesión perianal.

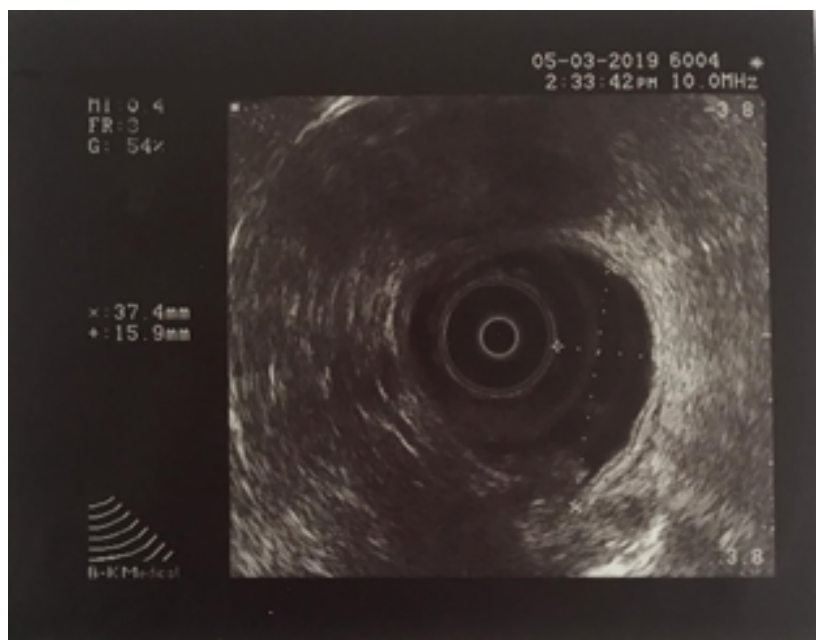

Figura 2: Ecografía $360^{\circ}$

tacto impresiona no estar adherida a planos profundos (Figura 1).

Se realiza una ecografía transanal de $360^{\circ}$, en la cual se observa a nivel bajo, una masa hipoecoica de $37 \times 15 \mathrm{~mm}$ que compromete al haz subcutáneo del esfínter anal externo (Figura 2). También se lleva a cabo una videocolonoscopía en la que se progresa hasta ciego sin encontrar otras lesiones.

Habiendo evaluado la lesión y descartado otras lesiones en el colon se realizó la escisión completa de la tumoración con márgenes libres de $1 \mathrm{~cm}$ (Figura 3).

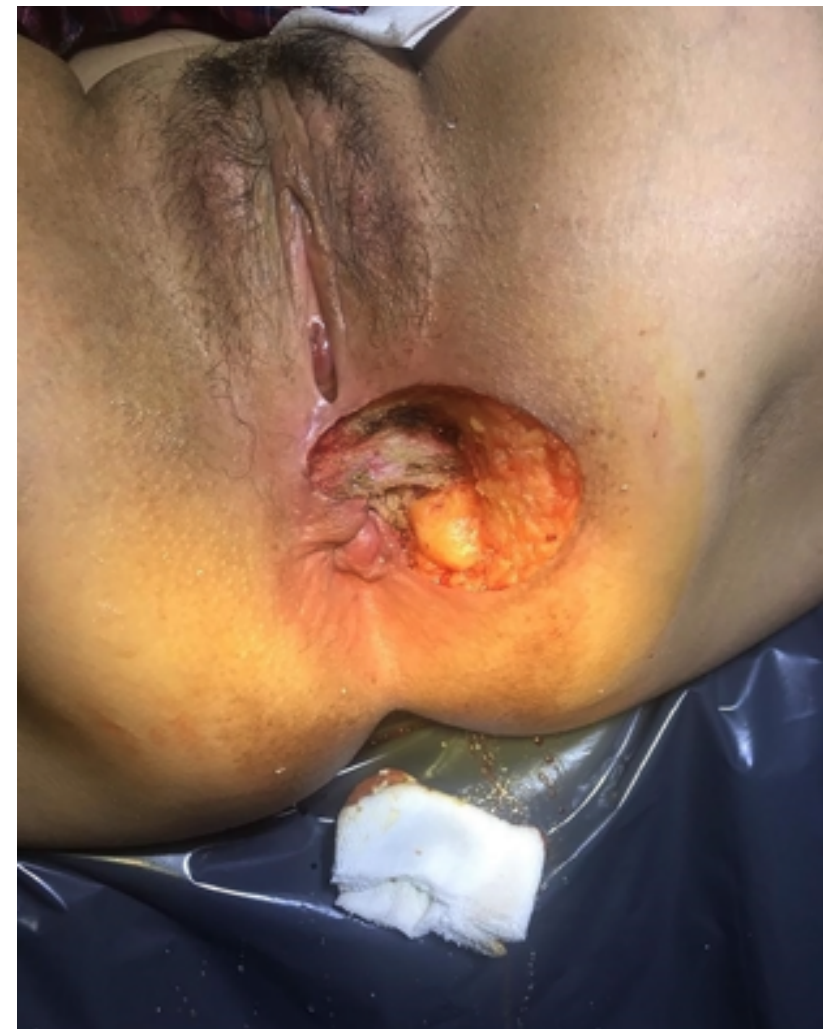

Figura 3: Resección completa.

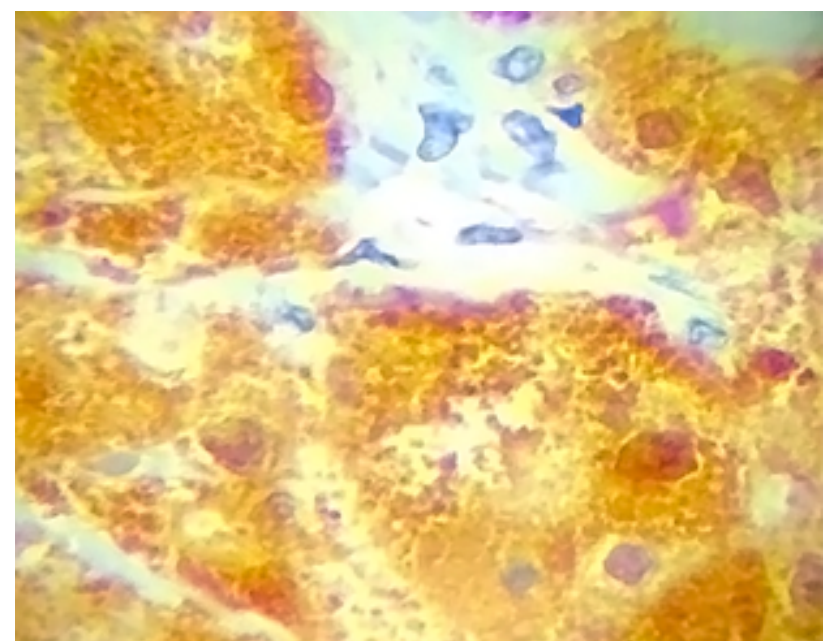

Figura 4: Microscopía.

Durante el postoperatorio la paciente cursa con buena evolución cicatrizando completamente la herida en 4 semanas. Ni en el examen físico ni en los estudios de imágenes se observó recurrencia local o diseminación a los dos meses desde la exéresis.

En el estudio histopatológico, la lesión fue caracterizada como revestida por epitelio pavimentoso con hiperplasia pseudoepiteliomatosa. No se observaron atipias citológicas, mitosis ni áreas de necrosis. Los márgenes de resección están libres de lesión (Figura 4).

Se realizaron técnicas de inmunohistoquímica y los 
marcadores realizados fueron S100 que resultó positivo, CD68 informado como positivo débil y Desmina, negativa (Figura 5). El diagnóstico histopatológico fue Tumor de Células Granulares.

\section{DISCUSIÓN}

Los TCG generalmente se limitan a la submucosa y se presentan como lesiones benignas, asintomáticas, pequeñas, no ulceradas, polipoideas, las cuales se encuentran en su mayoría de forma incidental en el examen proctológico. Cuando estas lesiones son mayores de $2 \mathrm{~cm}$ pueden presentar síntomas como sensación de bulto perianal, dolor y sangrado. Cuando el TCG perianal es sintomático, puede confundirse con un absceso organizado., ${ }^{3,49}$

En la tomografía computada, sus características son inespecíficas, se presenta como una masa de tejido blando heterogénea. Pueden ser difíciles de evaluar debido a su pequeño tamaño. ${ }^{8}$

Desde el punto de vista histopatológico, debido a la hiperplasia seudoepiteliomatosa y a la acantosis suprayacente que demuestra el TCG el principal diagnóstico diferencial que debe descartarse es el carcinoma de células escamosas (CCE). El TCG se diferencia del CCE por su queratina, desmina y patrón de tinción negativo de actina específico del músculo; por lo que el diagnóstico debe realizarse mediante biopsia y análisis histológico e inmunohistoquímico.,10,11,13

El diagnóstico histológico se puede confundir con otros procesos reactivos o condiciones neoplásicas que exhiben un citoplasma granular. Sin embargo, la tinción inmunohistoquímica disponible en la actualidad es extremadamente valiosa para establecer el diagnóstico diferencial ya que de manera característica S-100, vimentina y el marcador lisosomal CD68 se tiñen en el núcleo y en el citoplasma. $^{3,10,11}$

Cuando se observa una lesión sospechosa, la extirpación quirúrgica es obligatoria para el diagnóstico y tratamiento, el cual si bien puede ser curativo, exige un seguimiento estricto del paciente debido al potencial de malignidad, la posibilidad de metástasis y el riesgo de recurrencia que presenta. ${ }^{3,5}$

Aproximadamente, entre el 1-2 \% de los casos son malignos. ${ }^{3,5,12} \mathrm{El}$ diagnóstico diferencial entre lesiones benignas y malignas es a veces difícil debido a su apariencia histológica similar. El factor predictor de malignidad más importante es el tamaño, seguido por la histología atípica. ${ }^{3,11,12}$ Las lesiones benignas generalmente son menores de $3 \mathrm{~cm}$ y tienen, histológicamente, núcleos uniformes con ausencia de figuras mitóticas; mientras que de los casos malignos $60 \%$ eran lesiones mayores a $4 \mathrm{~cm} .{ }^{4,14}$

Las lesiones malignas pueden generar metástasis pul-

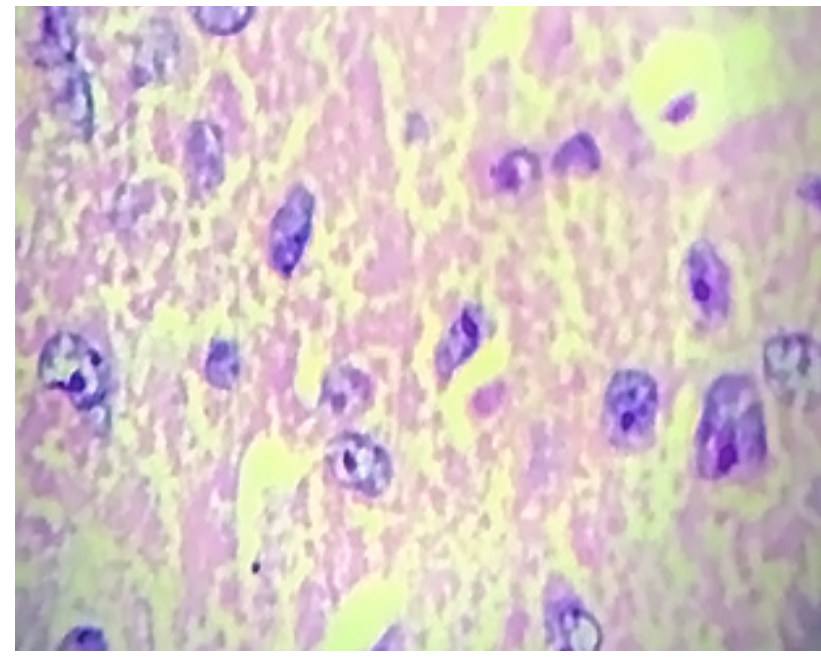

Figura 5: Inmunohistoquímica.

monares, hepáticas y óseas con una propagación linfática y hematógena típica. En la literatura hay reportados aproximadamente 50 casos de TCG malignos, de los cuales solo 3 casos fueron informados en la región anal y perianal. $^{15,16}$

No está claro si las lesiones malignas resultan de la transformación de lesiones benignas o comienzan como malignas y es debido a esto que la resección quirúrgica con márgenes libres es obligatoria al momento del diagnóstico para evitar la recurrencia local, la diseminación linfática y hematógena en casos malignos. ${ }^{3}$ Un TCG maligno puede parecer histológicamente idéntico a un TCG benigno y solo la aparición de metástasis conducirá a un diagnóstico posterior de malignidad.

El pronóstico del TCG maligno no es alentador, con una tasa de mortalidad global del 30 al $50 \%$. FanburgSmith17 informó que mientras la tasa de recurrencia a 2 años del TCG es del $32 \%$ para la enfermedad maligna, representa del 2 al $8 \%$ en aquellos con presentación benigna. Esta tasa puede aumentar al $20 \%$ en lesiones benignas con márgenes comprometidos. Por lo tanto, es extremadamente importante realizar una escisión local con un margen quirúrgico libre de enfermedad. ${ }^{6}$

Después de la resección, y más aún en aquellos con presentación maligna, se deben realizar exámenes complementarios para evaluar y descartar meticulosamente la recidiva local y la posibilidad de metástasis, debido a que ni la quimioterapia ni la radioterapia mejoran el pronóstico.,

\section{CONCLUSIÓN}

El TCG perianal es una lesión infrecuente y de difícil diagnóstico. Debido a esto, consideramos que debe tenerse presente al evaluar a un paciente con una lesión submucosa perianal asintomática o poco sintomática.

Es fundamental realizar una exéresis quirúrgica com- 
pleta con márgenes de resección libres, como también es de suma importancia el examen inmunohistoquímico para obtener un diagnóstico preciso y poder descartar al carcinoma de células escamosas que representa el principal diagnóstico diferencial.

Posterior al tratamiento quirúrgico es menester una vigilancia estrecha de los pacientes debido a que presenta una alta tasa de recurrencia y a que no hay características clínicas, radiológicas ni histológicas precisas que diferencien un TCG maligno de uno benigno. Durante este seguimiento debemos buscar recidiva local, diseminación ganglionar y enfermedad a distancia que caracterizan al TCG maligno y plantea un pronóstico poco alentador para el paciente.

\section{REFERENCIAS}

1. Abrikossoff AI. About fibromas of the striated muscles. Virchow Arch Path Anat 1926;260:215-33.

2. Rickert RR, Larkey IG, Kantor EB. Granular-cell tumors (myoblastomas) of the anal region. Dis Colon Rectum1978;21:413-17.

3. Mistrangelo M, Cassoni P, Scozzari G, Castellano I, Gavello G, Corno F, et al. Perianal granular cell tumor: report of a case and review of the literature. Tumori 2009;95:538-41.

4. Wan XY, Hu B, Zhou ZY, Huang Y, Ren DL. Recurrent granular cell tumor of the anal-perianal region: how much anal sphincter can be resected? Tech Coloproctol 2014;18:597-600.

5. Kelly EF, Stein AA, Ma XC, Yeguez J. A rare case of perianal granular cell tumor: case report and literature review. J Surg Case Rep 2017. DOI:10.1093/jscr/rjw186.

6. Ugur K, Emine M, Sevgi K, Sezgin Z. Granular cell tumor on perianal region: a case report. Acta Med Iran 2013;51:509-11.

7. Pérez-Flecha González M, Revilla Sánchez E, Ibarrola de Andrés C, et al. Granular cell tumor of the perianal region. J Gastrointest Surg 2020;24:907-08.

8. Rashidi L, Pollock D, Bastawrous S. Unexpected presentation of perianal granular cell tumor in a young woman. Curr Probl Diagn Radiol 2017;46:452-54.

9. Francesco VD, Avellini C, Pappalardo S, Proscia D, Piccirillo F. Malignant granular cell tumor of the anal-perianal region and suprarenal hyperplasia: a casual association? Indian J Dermatol
2010;55:403-5.

10. Sohn DK, Choi HS, Chang YS, et al. Granular cell tumor of colon: report of a case and review of literature. World J Gastroenterol 2004;10:2452-54

11. Ribeiro SPP, Levy SF, Corrêa FM, Sousa AM, da Costa Silveira F, Carvalho MR, et al. Granular cell tumor of rectal submucosa: case report. J Coloproctol 2015;35:124-27.

12. Cohen MG, Greenwald ML, Garbus JE, Zager JS. Granular cell tumor-a unique neoplasm of the internal anal sphincter: Report of a case. Dis Colon Rectum 2000;43:1444-46; discussion 1447.

13. Fujii T, Morita H, Yamaguchi S, Tsutsumi S, Asao T, Kuwano H. A rare case of granular cell tumor of the anal region: diagnostic difficulty to masses in the anal area. Int Surg 2014;99:45-7.

14. Mourra N, Werbrouck A, Bauer P. Anal region: an unusual location of granular cell tumour. Int J Colorectal Dis 2011;26:811-12.

15. Crowe D, Ayli EE, Gloster HM Jr. A malignant granular cell tumor excised with mohs micrographic surgery. Case Rep Oncol Med 2012;2012:453569.

16. Bouraoui S, Letaief H, Mestieri H, Chadly-Debbiche A, Ben Zineb S, Haouet S, et al. Malignant granular cell tumor. Report of a case of anal localization. Ann Pathol1999;19:151-52.

17. Fanburg-Smith JC, Meis-Kindblom JM, Fante R, Kindblom LG. Malignant granular cell tumor of soft tissue: diagnostic criteria and clinicopathologic correlation. Am J Surg Pathol 1998;22:779-94. 